\title{
Pregnancy-related knowledge of expectant fathers: a survey analysis
}

\begin{abstract}
Objective: To evaluate knowledge and attitude of male partners relative to pregnancy, pregnancy complications and childbirth.

Study design: A self-administered content specific 21-question survey was completed by 280 expectant fathers who attended prenatal visits with their pregnant partners at Duke Perinatal Clinic between July 2014 and September 2014 and February 2016 through June 2016. The survey tool assessed (1) paternal knowledge regarding pregnancy (normal and abnormal) and childbirth; (2) paternal expectations and role during the pregnancy and birth process using a Likert scale. Survey responses were stratified and analyzed by the primary variable of highest completed education level of the male partner (less than high school, high school, college, and graduate degree). Analysis modeling included a multivariable logistic regression to assess the association between paternal planned pregnancy and smoking status and paternal educational level while controlling for race and self-identified professional status. A p-value of $<0.05$ was considered significant. All statistical analysis was performed using Stata 14.
\end{abstract}

Results: The rate of unplanned pregnancy was significantly higher among those with less formal education. Cohort agreement with planned pregnancy ranged from $38.7 \%$ for less than High School $(<\mathrm{HS})$ to $83.7 \%$ Graduate Degree $(\mathrm{GD})(\mathrm{p}=0.0002)$.

Over $56 \%$ of male partners with lower education ( $<$ HS and HS) were current smokers compared to a $13.5 \%$ of men with a $\mathrm{C}$ and GD $(\mathrm{p}<0.0001)$. In a multivariate analysis, compared to individuals with a college degree or greater, male partners with less education have 7.97 (95\% CI 2.94, 21.61) odds of smoking during pregnancy when controlling for race and employment status. Of male partners $20.6 \%(<\mathrm{HS}), 26.6 \%(\mathrm{HS}), 25.3 \%(\mathrm{C})$ and $14.3 \%$ (GD), incorrectly identified a term pregnancy as 35 or 36 completed weeks. Most men regardless of education level were aware of specific weight gain recommendations for their partner. Those with $<$ HS and HS were more likely to indicate a healthy sexual relationship compared to those with $\mathrm{C}$ or GD. $(\mathrm{p}=0.007)$. There was no knowledge gap by education level in preeclampsia and the risk for mother and baby. Support for breast feeding was significantly different by education level with those male partners with HS or less being less supportive than those with $\mathrm{C}$ or GD level education. $(\mathrm{p}=0.019)$. Men with $<\mathrm{HS}$ and HS were not as aware of postpartum depression. $(\mathrm{p}=0.021)$.

Conclusions: Gaps in knowledge about pregnancy complications and maternal and partner health behaviors were identified by education level of the male partner which presents an opportunity for better engagement and education of the male partner during the preconception and prenatal periods.

Keywords: male partner, education level, pregnancy, knowledge
Volume 5 Issue I - 2019

\author{
Haywood L Brown, Benjamin S Harris, Chad \\ A Grotegut, Eve Hamlett, Maria J Small \\ Department of Obstetrics and Gynecology, Duke University \\ School of Medicine, USA
}

Correspondence: Haywood L Brown, MD, Professor and Chair Emeritus, Department of Obstetrics and Gynecology, Duke University, DUMC Box 3084, Durham, NC 27I 10, USA, Tel 919-668-3948, Fax: 919-668-5547,

Email Haywood.brown@duke.edu

Received: January 10, 2019 | Published: February 04, 2019

\section{Introduction}

Over the last several decades, a father's role in childcare has evolved from a traditional expectation of western societies (of the father being relegated to "just the bread winner") to one of being more involved with childbirth and child rearing. During the 1970's and 1980's it was expected that the male partner would attend childbirth education classes. Childbirth education has evolved over the last three decades and has become more family- centered. It is now the expectation that most fathers will enter the delivery room in a supporting role during childbirth and participate in some aspects as a coach during labor and delivery, (ex. cutting of the umbilical cord). The father's presence at birth various from country to country and by ethnic group. ${ }^{1}$ (Redshaw and Henderson 2013) In many settings the labor and delivery area still excludes male participation. In some settings this occurs due to cultural traditions and in other settings limited resources do not allow for patient privacy so males not involved in maternal care are excluded. ${ }^{2}$

While childbirth education has evolved to be more familycentered, a summary from Sweden suggests that prospective fathers still report feeling marginalized in this female-dominated arena. ${ }^{3}$ In a study by Johnson, $50 \%$ of men expressed they felt pressure to be present at the birth not only from their partner but also the birth attendant/midwife. ${ }^{4}$

The father's participation in and understanding of pregnancy and the birth process is important to a healthier childbirth experience for the couple and to birth outcome. ${ }^{5,6}$ Paternal involvement in pregnancy positively influences maternal health behaviors and thereby diminishes risk of preterm birth and other negative infant outcomes. ${ }^{7}$ (Shah) Obviously, there are a number of confounding paternal and maternal factors that impact birth outcome including race and education. In the 
systematic review by Shah et al, less than a high school education was associated with a higher rate of preterm birth, and less than a college level education was associated with higher odds for low birth weight infants. $^{7}$

Pregnancy and childbirth can be a stressful time for expectant parents. The expectant father plays a critical role in supporting the mother during the pregnancy, labor and delivery and postpartum. For example, the father's attitude about breastfeeding has a significant impact on the mother's decision to breast feed as well as contraceptive choices. $^{8-12}$ Expectant parents, especially the father- to-be may feel ill-prepared for pregnancy complications that threaten maternal and infant health and well-being. ${ }^{13}$

Our objective was to better understand the male partner's knowledge related to certain aspects of normal and abnormal pregnancy and childbirth, and to gain a perspective of the male partners' expectations of their role during the pregnancy and the birth process.

\section{Materials and methods}

\section{Study protocol}

Survey data was collected from 280 expectant fathers who attended prenatal encounters at Duke Perinatal Clinic between July and September 2014 and February through May 2016. The 'expectant father' was defined as the male partner of the index pregnancy. The study protocol was reviewed and approved by the Duke University Institutional Review Board as exempt research. Participants completed the survey independently from the mother (i.e. the patient). Data was recorded anonymously with no linkage to any protected health information.

The survey included a cover sheet with a place for the father to include his name as an option. Surveys were pre-labeled with a unique study identification number to be used only for accurate data entry and management using REDCap hosted at Duke University. ${ }^{10}$ Given that the survey was performed anonymously with no linkage to any protected health information, written informed consent was not obtained.

\section{Survey instrument}

The survey (Appendix A) included demographic information and questions directed toward assessing the following: (1) paternal knowledge regarding pregnancy (normal and abnormal) and childbirth; (2) paternal expectations and role during the pregnancy and birth process. The survey instrument contained 21 contentspecific Likert scale questions. Question stems fell into three separate themes: Pregnancy Planning, Delivery, and Postpartum. Data was collected on the following demographic variables: Race/Ethnicity (non-Hispanic white, non-Hispanic black, Hispanic, Asian, Native American, and Asian/Indian, other), Education (less than high school, high school, college, and graduate degree), Marital Status (single, married, remarried, not married but living with partner), Employment (white collar, blue collar, or unemployed).

\section{Statistical analysis}

Survey responses were compiled and stratified by paternal educational level. Associations among paternal responses and educational level were analyzed using Chi square or Fisher's exact testing. Univariable analysis was used to examine demographic variable distributions across the entire population and then by education status. Multivariable logistic regression was used to analyze the association between paternal prenatal smoking (current smoker and quit during pregnancy) and educational level (Less than High
School and High School vs. College and Graduate Degree) while controlling for race. Additionally, this modeling was used to analyze the association between paternal pregnancy planning and educational level, while controlling for race. A p-value of $<0.05$ was considered significant. All statistical analysis was performed using Stata 14.

\section{Results}

Basic demographic information is showed in Table 1. The average age of respondents was $31.4 \pm 6.5$ years and $52.5 \%$ were African American. Survey participants were more likely to be married $(42.5 \%)$, highest level of completed education was high school $(39.6 \%)$, self identified blue collar employment (41.4\%), and to have a pregnant partner with a gestational age $>29$ weeks $(42.1 \%)$ at the time of survey completion.

Prenatal Knowledge and Attitudes are shown in Tables $2 \& 3$.

Table I Baseline demographic data

\begin{tabular}{|c|c|}
\hline Demographics & $\mathbf{N}=\mathbf{2 8 0}$ \\
\hline Age, years & $31.4 \pm 6.5$ \\
\hline \multicolumn{2}{|c|}{ Current gestational age of pregnancy } \\
\hline$<12$ weeks(3 months) & $52(18.6)$ \\
\hline I3-28 weeks(4-7 months) & $94(33.6)$ \\
\hline$>29$ weeks(> 7 months) & $118(42.1)$ \\
\hline \multicolumn{2}{|l|}{ Race/Ethnicity } \\
\hline Caucasian & $100(35.7)$ \\
\hline African American & $147(52.5)$ \\
\hline Hispanic & $10(3.6)$ \\
\hline Asian & $8(2.9)$ \\
\hline Native American & $8(2.9)$ \\
\hline Asian/Indian & $4(1.4)$ \\
\hline Not reported & $7(2.5)$ \\
\hline \multicolumn{2}{|l|}{ Marital Status } \\
\hline Single & $81(28.9)$ \\
\hline Not married, live together & $64(22.9)$ \\
\hline Married & $119(42.5)$ \\
\hline Remarried & II(3.9) \\
\hline Not reported & $5(1.8)$ \\
\hline \multicolumn{2}{|l|}{ Education } \\
\hline Less than high school & $31(11.1)$ \\
\hline High school & III(39.6) \\
\hline College & $93(33.2)$ \\
\hline Graduate degree & $43(15.3)$ \\
\hline Not reported & $2(0.7)$ \\
\hline \multicolumn{2}{|l|}{ Profession } \\
\hline White collar & $96(34.3)$ \\
\hline Blue collar & $1 \mid 6(4 \mid .4)$ \\
\hline Unemployed & $40(14.3)$ \\
\hline First child with this partner & $|8|(64.6)$ \\
\hline Other children & $150(54.1)$ \\
\hline
\end{tabular}


Table 2 Prenatal Education and Attitudes by Highest Achieved Level of Education

\begin{tabular}{|c|c|c|c|c|c|}
\hline & $\begin{array}{l}\text { Less than HS } \\
\mathbf{N}=3 \text { I }\end{array}$ & $\begin{array}{l}\text { HS } \\
N=|| ~ I ~\end{array}$ & $\begin{array}{l}\text { College } \\
N=93\end{array}$ & $\begin{array}{l}\text { Graduate degree } \\
N=43\end{array}$ & p-value \\
\hline Planned pregnancy & & & & & 0.0002 \\
\hline Agree & $12(38.7)$ & $46(4 I .8)$ & $48(51.6)$ & $36(83.7)$ & \\
\hline Disagree & $10(32.3)$ & $28(25.4)$ & $20(21.5)$ & $4(9.3)$ & \\
\hline Neither agree or disagree & $9(29.0)$ & $36(32.7)$ & $25(26.9)$ & $3(7.0)$ & \\
\hline Not planned but wanted & & & & & 0.0001 \\
\hline Agree & $22(75.9)$ & $66(62.3)$ & $38(44.2)$ & $\mathrm{II}(3 \mathrm{I} .4)$ & \\
\hline Disagree & $\mathrm{I}(3.4)$ & $24(22.6)$ & $28(32.6)$ & $17(48.6)$ & \\
\hline Neither agree or disagree & $6(20.7)$ & $16(15.1)$ & $20(23.3)$ & $7(20.0)$ & \\
\hline Excited to be a new father & & & & & 0.68 \\
\hline Agree & $30(96.8)$ & $108(98.2)$ & $91(97.8)$ & $4 I(95.3)$ & \\
\hline Disagree & $0(0)$ & $0(0)$ & $0(0)$ & $\mathrm{I}(2.3)$ & \\
\hline Neither agree or disagree & $\mathrm{I}(3.2)$ & $2(1.8)$ & $2(2.1)$ & $\mathrm{I}(2.3)$ & \\
\hline Look forward to attending PN visit & & & & & 0.48 \\
\hline Agree & $28(90.3)$ & $106(95.5)$ & $91(97.8)$ & $40(93.2)$ & \\
\hline Disagree & $0(0)$ & $\mathrm{I}(0.9)$ & $0(0)$ & $0(0)$ & \\
\hline Neither agree or disagree & $3(9.7)$ & $4(3.6)$ & $2(2.1)$ & $3(7.0)$ & \\
\hline
\end{tabular}

p-values are based on Pearson's chi-square or Fisher's exact testing.

Table 3 Pregnancy knowledge

\begin{tabular}{|c|c|c|c|c|c|}
\hline & $\begin{array}{l}\text { Less than HS } \\
\mathbf{N}=3 \text { I }\end{array}$ & $\begin{array}{l}\mathbf{H S} \\
\mathbf{N}=|| \mid\end{array}$ & $\begin{array}{l}\text { College } \\
N=93\end{array}$ & $\begin{array}{l}\text { Graduate degree } \\
N=43\end{array}$ & p-value \\
\hline Familiar with how much weight gain should gain & & & & & 0.36 \\
\hline Agree & $22(71.0)$ & $74(68.5)$ & $65(71.4)$ & $36(85.7)$ & \\
\hline Disagree & $2(6.4)$ & $\mathrm{II}(\mathrm{I0.2)}$ & $10(11.0)$ & $3(7.1)$ & \\
\hline Neither agree or disagree & $7(22.6)$ & $23(21.3)$ & $16(17.6)$ & $3(7.1)$ & \\
\hline Recommended weight gain for my partner & & & & & 0.50 \\
\hline$<30$ pounds & $9 / 17(52.9)$ & $40 / 63(63.5)$ & $40 / 59(67.8)$ & $25 / 34(73.5)$ & \\
\hline$>30$ pounds & $8 / 17(47.1)$ & $23 / 63(36.5)$ & $19 / 59(32.2)$ & $9 / 34(26.5)$ & \\
\hline Father smoking status & & & & & $<0.0001$ \\
\hline Never smoked & $4(12.9)$ & $17(15.4)$ & $33(35.5)$ & $22(51.2)$ & \\
\hline Non-smoker & $8(25.8)$ & $23(20.9)$ & $40(43.0)$ & $15(34.9)$ & \\
\hline Quit before pregnancy & $3(9.7)$ & $8(7.3)$ & $2(2.1)$ & $4(9.3)$ & \\
\hline Quit during pregnancy & $3(9.7)$ & $4(3.6)$ & $5(5.4)$ & $0(0)$ & \\
\hline Smoker & |3(4|.9) & $58(52.7)$ & $13(\mid 4.0)$ & $2(4.6)$ & \\
\hline $\begin{array}{l}\text { Aware that maternal smoking and passive smoking } \\
\text { fetal, infant/childhood conditions }\end{array}$ & & & & & 0.074 \\
\hline Agree & $29(96.7)$ & $101(92.7)$ & $91(97.8)$ & $43(100)$ & \\
\hline Disagree & $\mathrm{I}(3.3)$ & $\mathrm{I}(0.9)$ & $0(0)$ & $0(0)$ & \\
\hline Neither agree or disagree & $0(0)$ & $7(6.4)$ & $2(2.1)$ & $0(0)$ & \\
\hline
\end{tabular}

p-values are based on Pearson's chi-square or Fisher's exact testing. 


\section{Pregnancy planning}

The rate of unplanned pregnancy was significantly higher among the cohort with less formal education when compared to fathers with at least a college education or graduate degree. Cohort agreement with planned pregnancy ranged from $38.7 \%(<\mathrm{HS})$ to for $83.7 \%(\mathrm{GD})$ respectively $(\mathrm{p}=0.0002)$. However, when asked whether an unplanned pregnancy was wanted, $75.9 \%(<\mathrm{HS})$ agreed compared to $62.3 \%$ (HS), 44.2\% (C) and 31.4\% (G), respectively. $(\mathrm{p}=0.0001)$ In our population, fathers with a college degree or greater have $3.58(95 \%$ CI $1.39,7.81)$ times the odds of having a planned pregnancy when controlling for race.

Over $95 \%$ of all male partners agreed they were excited about the prospects of being a father and looked forward to seeing the fetus on ultrasound and over $90 \%$ agreed that they looked forward to attending prenatal visits with their partner. Lack of gender preference was similar amongst fathers despite different educational levels.

\section{Sexual relationship}

There was a significant difference in agreement by level of education with regard to those who indicated a healthy sexual relationship during pregnancy. Those with $<$ HS and HS were more likely to indicate a healthy sexual relationship compared to those with College or Graduate education. $(p=0.007)$

Most men regardless of education level were aware of specific weight gain recommendations for their partner and between $38.7 \%$ $(<$ HS $)$ and more than half of HS and college agreed that they too had gained weight (Table 3).

\section{Paternal smoking}

Over $56 \%$ of male partners with lower education $(<\mathrm{HS}$ and HS) were current smokers compared to a $13.5 \%$ of men with a college degree or greater $(\mathrm{p}<0.0001)$. Among the less educated cohort, $85 \%$ reported awareness of maternal and passive smoking effects on birth weight and infant/childhood conditions. All fathers with a college degree or greater, reported such awareness $(p=0.035)$ (Table 3$)$. The bivariate analysis of current smoking rates by level of education was notable for significantly higher rates of smoking in those with less than college education ( 50 vs. $11 \%, \mathrm{p}<0.0001$ ). In a multivariate analysis, compared to individuals with a college degree or greater, those male partners with less education have 7.97 (95\% CI 2.94, 21.61) odds of smoking during pregnancy when controlling for race and employment status. Ninety percent of each educational cohort $(<\mathrm{HS}$ and HS vs. College and Grad School) reported awareness of the adverse effects of smoking.

\section{Labor and delivery participation and epidural analgesia}

More than $80 \%$ of all men agreed they intended to participate as a coach during labor and planned to cut the cord. There was no difference in agreement with the partner having and epidural during labor and delivery by male partner education level.

\section{Knowledge of pregnancy complications}

Table 4 shows knowledge about pregnancy and complications by male partner education level. Knowledge of what is considered a term gestation; 37 completed weeks was not significantly different based on paternal education level. However, it is interesting that $20.6 \%(<\mathrm{HS}), 26.6 \%(\mathrm{HS}), 25.3 \%(\mathrm{C})$ and $14.3 \%(\mathrm{G})$, respectively, incorrectly identified a term pregnancy as 35 or 36 completed weeks.

There was no knowledge gap by education level in preeclampsia and the risk for mother and baby. Between $61.9 \%$ (Graduate) and $68.8 \%$ (College) of men had heard of preeclampsia and agreed that this pregnancy complication could potential pose risk to the mother and infant.

Table 4 Pregnancy Complications and Delivery expectation by Education level

\begin{tabular}{|c|c|c|c|c|c|}
\hline & Less than HS & HS & College & Graduate degree & p-value \\
\hline & $\mathbf{N}=3 \mathbf{I}$ & $N=|I|$ & $N=93$ & $N=43$ & \\
\hline GA of a term birth & & & & & 0.16 \\
\hline 35 weeks & $4 / 29(13.8)$ & $10 / 105(9.5)$ & $3 / 91(3.3)$ & $1 / 42(2.4)$ & \\
\hline 36 weeks & $2 / 29(6.9)$ & $18 / 105(17.1)$ & $20 / 91(22.0)$ & $5 / 42(11.9)$ & \\
\hline 37 weeks & $3 / 29(10.3)$ & $16 / 105(15.2)$ & $16 / 91(17.6)$ & $10 / 42(23.8)$ & \\
\hline 38 weeks & $20 / 29(69.0)$ & $61 / 105(58.1)$ & $52 / 91(57.1)$ & $26 / 42(61.9)$ & \\
\hline \multicolumn{3}{|c|}{ Aware of preeclampsia/ risk for mom and baby } & & & 0.74 \\
\hline Agree & $19(63.3)$ & $69(63.3)$ & $64(68.8)$ & $26(61.9)$ & \\
\hline Disagree & $3(10.0)$ & $21(19.3)$ & $15(16.1)$ & $7(16.7)$ & \\
\hline Neither agree or disagree & $8(26.7)$ & $19(17.4)$ & $14(15.0)$ & $9(21.4)$ & \\
\hline \multicolumn{3}{|c|}{ I have heard of postpartum depression } & & & 0.021 \\
\hline Agree & $27(87.1)$ & $85(78.7)$ & $84(91.3)$ & $42(97.7)$ & \\
\hline Disagree & $2(6.4)$ & $13(\mid 2.0)$ & $5(5.4)$ & $\mathrm{I}(2.3)$ & \\
\hline Neither agree or disagree & $2(6.4)$ & $10(9.3)$ & $3(3.3)$ & $0(0)$ & \\
\hline
\end{tabular}

p-values are based on Pearson's chi-square or Fisher's exact testing. 
Those men with $<$ HS and HS were not as aware of postpartum depression. $(p=0.021)$. Table 5 discusses attitudes about breastfeeding. Most men regardless of level of education were supportive of their pregnant partners' desire to breastfeed. However, that support was significantly different by education level with those male partners with HS or less being less supportive than those with college or graduate level education. $(\mathrm{p}=0.019)$. Between $83.9 \%(<\mathrm{HS})$ and $95.3 \%$ (Graduate) agreed that there were long-term health benefits of breast-feeding for both the mother and baby.

Table 5 Postpartum knowledge by Education

\begin{tabular}{|c|c|c|c|c|c|}
\hline & Less than HS & HS & College & Graduate degree & p-value \\
\hline & $\mathbf{N}=\mathbf{3}$ I & $\mathbf{N}=\mathbf{I}$ I & $\mathbf{N}=93$ & $\mathbf{N}=43$ & \\
\hline \multicolumn{5}{|l|}{ Support desire to breastfeed } & 0.019 \\
\hline Agree & $25(80.6)$ & $98(88.3)$ & $88(94.6)$ & $42(97.7)$ & \\
\hline Disagree & $\mathrm{I}(3.2)$ & $4(3.6)$ & $0(0)$ & $\mathrm{I}(2.3)$ & \\
\hline Neither agree or disagree & $5(16.1)$ & $9(8.1)$ & $5(5.4)$ & $0(0)$ & \\
\hline \multicolumn{5}{|c|}{ Aware of health benefits for mom and infant to breast feeding } & 0.25 \\
\hline Agree & 26(83.9) & $93(84.5)$ & $86(92.5)$ & $4 I(95.3)$ & \\
\hline Disagree & $0(0)$ & $2(1.8)$ & $\mathrm{I}(\mathrm{I} . \mathrm{I})$ & $0(0)$ & \\
\hline Neither agree or disagree & $5(16.1)$ & $15(13.6)$ & $6(6.4)$ & $2(4.6)$ & \\
\hline \multicolumn{5}{|c|}{ Healthy sexual relationship during the pregnancy } & 0.007 \\
\hline Agree & $26(86.7)$ & $88(80.0)$ & $61(66.3)$ & $30(69.8)$ & \\
\hline Disagree & $0(0)$ & $6(5.4)$ & $18(19.6)$ & $8(18.6)$ & \\
\hline Neither agree or disagree & $4(13.3)$ & $16(\mid 4.5)$ & $13(14.1)$ & $5(11.6)$ & \\
\hline
\end{tabular}

p-values are based on Pearson's chi-square or Fisher's exact testing.

\section{Discussion}

This survey suggests a knowledge gap about pregnancy and pregnancy complications based on the level of education achieved for the male partners. The survey indicated that the majority of men identified themselves as married, remarried or living with the current partner. This finding implies a stable, committed relationship and household. With regard to pregnancy planning, those with less educational achievement were more likely to agree that the pregnancy was not planned. However, a somewhat ambivalent findings was those less educated men were also more likely than those with higher education to agree that although the pregnancy was unplanned, it was wanted. For example, $38.7 \%$ of men with less than a high school education indicated that the pregnancy was planned compared to $83.7 \%$ of men with a graduate degree. Whereas, $75.9 \%$ of men with less than high school indicated that the pregnancy was not planned the pregnancy was wanted compared to only $31.4 \%$ of those men with a graduate degree.

Knowledge of what constitutes a term gestation and knowledge of pregnancy complications such as preeclampsia and postpartum depression produced some interesting findings on agreement by education level. Male partner's knowledge of complications such as preterm birth, preeclampsia and postpartum depression are important since these complications are associated with both maternal and fetal morbidities that impact the psychosocial health and the dynamics of the family. There was no difference by education level with regard to knowledge of a term pregnancy. What was surprising is that nearly $15 \%$ of men with a college degree incorrectly designated 35 or 36 completed weeks as term and the rate of incorrect identification of term was more than $20 \%$ for those least educated and those college educated. Preterm birth is a leading cause for perinatal morbidity and mortality and racial and socio demographic disparity. There is a need for better paternal education because of the challenges to the couple's relationship and family when a preterm birth occurs. Similarly, preeclampsia particularly, preeclampsia with severe features occurring prior to term impacts both maternal and perinatal morbidity and mortality. There was no knowledge gap by education level in preeclampsia and the risk for mother and baby but surprisingly that knowledge was only in the $60 \%$ range for all education levels.

Most men regardless of education level were aware that there was specific weight gain recommendations for their partner although they were less sure of how much weight their partner should gain when evaluated by less than or greater than 30 pounds. Those men with high school education and less were not as aware of postpartum depression but overall knowledge was high which is interpreted as a positive finding in the survey. Postpartum depression is one of the most common complications of childbirth. ${ }^{16}$ The estimates rate of postpartum depression is between 10 to $20 \%$ of women who give birth each year. ${ }^{17}$ Rates may be even higher for minority women and those who experience a pregnancy complication. ${ }^{18}$ Postpartum depression has a significant impact on the parenting couple and the partner's ability to identify the warning signs of depression and to provide support during this stressful period is critical to the future health of the family. There is also a relationship maternal postpartum depression and paternal postpartum depression which can range from up to $24 \%$ to $50 \%{ }^{19}$

In our survey, the majority of men regardless of educational level agreed that there were health benefits to breastfeeding for both mother and baby. However, less educated men were less likely to be supportive of the decision of their partner to breastfeed. Breastfeeding education during the prenatal period that includes the short and long 
term health benefits for both mother and child should include both perspective parents. Seventy five percent of women make decision about breastfeeding before pregnancy or in first trimester. In a study by Arora el al $40 \%-75 \%$ of women report that their perceptions of the partner's opinion or preference impact the decision about breastfeeding. ${ }^{8}$ Past reports suggest a number of male misconceptions about breastfeeding including formula being more healthy and better for the infant. Also there was an impression by male partners that breastfeeding made the breast less attractive, unappealing and interferes with postpartum sexuality. ${ }^{8}$ Such misperceptions were not addressed in our survey however this could be incorporated in the prenatal education of breastfeeding especially for male partners who are ambivalent as appeared to have been the case for those male partners with lower education attainment in this survey. We are encouraged that male partners regardless of education level or race were supportive of their partners desire to breast fed and realized both the short and long term health benefits of breastfeeding.

We decided to investigate couples' intimate relationship by addressing sexual satisfaction by education level of the male partner. This was the male partners' perception of having a healthy sexual relationship rather than the couples or female partners impression of the sexual relationship. Less educated men, HS or $<$ HS were more likely to agreed that they enjoyed a healthy sexual relationship compared to men with higher education.

There is the potential for post-traumatic stress for both the father and the mother after a difficult birth and the couple's sexual relationship can be adversely affected by the fathers attendance and witnessing of the. ${ }^{10}$ Among fathers reporting psychological and sexual scarring after observing childbirth many were likely vulnerable prior to watching the birth. ${ }^{16,17}$ It is reasonable to explore the emotional vulnerabilities of the couple's intimate relationship during the prenatal period so that counseling and intervention strategies can be implemented if sexual intimacy becomes a concern postpartum. ${ }^{17}$

The greatest opportunity for education of the male partner is with the impact of smoking and second hand smoking on perinatal health. In our study, more than $50 \%$ of men with a high school education or less were smokers despite the knowledge of the negative effects of smoking on pregnancy. When race and self-identified employment status were incorporated as variables those men with less education more six times more likely to smoke. Therefore, education on the impact of maternal and passive smoking on low birthweight, prematurity, and neonatal and post-neonatal infant mortality is important especially for African American women who have greater risk for prematurity and low birth weight.

Our survey of male partners indicates opportunities for better engagement and inclusion of the partner about pregnancy, pregnancy complications and expectations during the prenatal, intrapartum and postpartum periods. Providers should take the opportunity to engage the partner and encourage input when an opportunity presents especially when counseling on weight gain, breast feeding and risk recurrence of pregnancy complications such as preterm birth, preeclampsia and postpartum depression.

This study has several strengths of which is notably the diversity of the male partner cohort by education level, racial and employment demographics. Another strength is the fact that the survey was self administered on site at the time of a visit and the male partner was asked to complete the survey without input from the female partner or members of the care delivery team. The study also reflects the views of men who were present for a prenatal or ultrasound appointment.
As such a potential bias is that this group of fathers may already be selectively more engaged than fathers who may not attend any antenatal care visits. A potential weakness is that there was no attempt to correlate survey responses to pregnancy and postpartum outcomes. We acknowledge that the study was not designed for such an assessment but nonetheless is a missed opportunity considering the heterogeneity of the population surveyed (Appendix).

The findings in the survey suggest an opportunity to interject specific dialogue in prenatal education geared toward the male partner and his concerns regarding pregnancy and parenting.

\section{Acknowledgments}

Special thanks to the Nursing Assistants at Duke Perinatal who assisted in the recruitment of male partners.

\section{Conflicts of interest}

The authors report no conflict of interest.

\section{References}

1. Redshaw MHJ. Fathers' engagement in pregnancy and childbirth: evidence from a national survey. BMC Pregnancy and Childbirth. 2013;13(70):1-15.

2. MF J. Fathers in the Caribbean have to fight to see the birth of their kids. PRI, Health \& Medicine: Global Voices on Line. 2014.

3. Premberg A LIFeoce. Fathers' experiences of childbirth education. Journal of Perinatal Education. 2006;15(2):21-28.

4. MP J. An exploration of men's experience and role at childbirth. The Journal of Men's studies. 2002;10(2):165-182.

5. Alio AP KJ, Mbah AK. The impact of paternal involvement on fetoinfant morbidities among whites, blacks and Hispanics. Matern Child Health. 2010;14(5):735-741.

6. Austin MP LL. Maternal stress and obstetric and infant outcomes: epidemiological findings and neuroendocrine mechanisms. Aust $N \mathrm{ZJ}$ Obstet Gynaecol. 2000;40(3):331-337.

7. Shah PS. Paternal factors and low birthweight, preterm and small for gestational age births: a systematic review. Am J Obstet Gynecol. 2010;202:103-123.

8. Arora S MC, Wehrer J, Kuhn P. Mother's perception of father's attitude and mild supply. Pediatrics 2000;106(5):e67.

9. Tohotoa J MB, Hauck YL, Howat P, et al. Dads make a difference: an exploratory study of paternal support for breastfeeding in Perth, western australia. Int Breastfeed J. 2009;29;4:15.

10. Harris P TR, Thielke R, Payne J, et al. Research electronic data capture (REDCAP)--A metadata-driven methodology and workflow process for providing translational research informatics support. J Biomed Inform. 2009;42(2):377-381.

11. Filner LB ZM. Unintended pregnancy in the United States: incidence and disparities. Contraception. 2006;84:478.

12. ACON. The importance of preconception care in the continuum of women's health care. Obstet Gynecol. 2005;106:665-666.

13. Ingram J JD. A feasibility study of an intervention to enhance family supporty for breastfeeding in a deprived area in Briston, UK. Midwifery. $20 ; 4: 367-379$.

14. Shepard CK PK, Carter H. Journal of Advanced Nursing. 20;31:651-660.

15. M O. Is the fatherss" participation at birth dangerous? Midwifery Today. 1999;51:23-25. 
16. Madsen SA JT. Paternal depression in the postnatal period assessed with traditional and male depression scale. Journal of Men's Health and Gender. 2007;4(1):26-31.

17. White G. You cope by breaking down in private: fathers and PTSD following childbirth. British Journal of Midwifery. 2007;15(1):39-45.
18. VL H. Sexual function and childbirth. Semin Perinatol. 2006;30:253256.

19. Rogers RG BN, Leeman LM Alber LL. Does spontaneous genital tract trauma impact postpartum sexual function? J Midwifery Womens Health. 2009;54(2):98-103. 